\title{
Effect of Alkyl Chain Length on Interfacial Performance of Alkyl Gallates in Supramolecular Oxidation of Soybean Bulk Phase Oil
}

\author{
Mojtaba Delfanian ${ }^{1}$, M. A. Sahari ${ }^{2}$, Mohsen Barzegar ${ }^{1}$, Hassan Ahmadi Gavlighi ${ }^{1}$, and \\ Francisco Jose Barba ${ }^{3}$ \\ ${ }^{1}$ Tarbiat Modares University \\ ${ }^{2}$ Affiliation not available \\ ${ }^{3}$ Universidad de Valencia Facultat de Farmacia
}

December 7, 2021

\begin{abstract}
From an interfacial phenomena standpoint, the effect of length of alkyl chain was evaluated on activities of gallic acid and its alkyl ester derivatives in supramolecular oxidation of stripped soybean oil. The gallic acid molecules $(\log \mathrm{P}=-0.47)$ with an electron-donating carboxylate anion had a higher scavenging activity against DPPH* than alkyl gallates. Interfacial activities of gallates in emulsion and bulk oil improved as the lengths of the alkyl chain were reached until a critical chain length; after that, further chain length extension causes a decrease in potency. In $\beta$-carotene bleaching and Rancimat assays higher inhibitory effect was observed for dodecyl and propyl gallate, respectively. Evaluation of interfacial tension, water content, and droplet size of hydroperoxides reverse micelles in parallel with lipid peroxidation indicated that the inhibitory effect of the alkyl gallates, especially methyl gallate, was significantly better than the gallic acid in the bulk phase oil.
\end{abstract}

Effect of Alkyl Chain Length on Interfacial Performance of Alkyl Gallates in Supramolecular Oxidation of Soybean Bulk Phase Oil

Running title: Interfacial phenomenon in bulk oil peroxidation

Mojtaba Delfanian $^{\mathrm{a}}$, Mohammad Ali Sahari ${ }^{\mathrm{a} *}$, Mohsen Barzegar ${ }^{\mathrm{a}}$, Hassan Ahmadi Gavlighi ${ }^{\mathrm{a}}$, Francisco J. Barba ${ }^{\mathrm{b}}$

${ }^{a}$ Department of Food Science and Technology, College of Agriculture, Tarbiat Modares University, P. O. Box 14115-336, Tehran, Iran

${ }^{b}$ Nutrition and Food Science Area, Faculty of Pharmacy, Universitat de València, Avda. Vicent Andrés Estellés, s/n 46100 Burjassot, València, Spain

* Corresponding author: E-mail address: sahari@modares.ac.ir

Tel: +98-21-48292328, Fax: +98-21-28292200

Highlights

- Assessment of innate potency of gallic acid and alkyl gallate in donating $\mathrm{H} / \mathrm{e}^{-}$.

- The role of alkyl chain length in interfacial activity of antioxidants.

- Kinetic study of the effect of lipophilic antioxidants on the oil oxidative stability.

- Lipid oxidation prediction based on the changes in water content, interfacial tension, and particle size.

Abstract 
From an interfacial phenomena standpoint, the effect of length of alkyl chain was evaluated on activities of gallic acid and its alkyl ester derivatives in supramolecular oxidation of stripped soybean oil. The gallic acid molecules $(\log P=-0.47)$ with an electron-donating carboxylate anion had a higher scavenging activity against $\mathrm{DPPH}^{*}$ than alkyl gallates. Interfacial activities of gallates in emulsion and bulk oil improved as the lengths of the alkyl chain were reached until a critical chain length; after that, further chain length extension causes a decrease in potency. In $\beta$-carotene bleaching and Rancimat assays higher inhibitory effect was observed for dodecyl and propyl gallate, respectively. Evaluation of interfacial tension, water content, and droplet size of hydroperoxides reverse micelles in parallel with lipid peroxidation indicated that the inhibitory effect of the alkyl gallates, especially methyl gallate, was significantly better than the gallic acid in the bulk phase oil.

Keywords: Association colloids, Interfacial activity, lipophilic antioxidant, Oxidation kinetics, Reverse micelle.

\section{Introduction}

The autoxidation of lipid, the reaction of unsaturated fatty acids by oxygen in lipid systems, is the most common chemical reaction that leads to severe losses in the sensory attributes, quality of nutrition, shelf-life, and safety of food systems. The free radicals formed during lipid oxidation also damage the different body's cells and cause countless diseases like cardiovascular disease, cancer, and immune system deficiencies. In the oil industry addition of antioxidant agents is the most common way to prevent lipid oxidation. Considering to carcinogenic effects of synthetic antioxidants, choosing a natural antioxidant with suitable antiradical capacity is a significant challenge in the oil industry. Enhancing the understanding of how physical attributes affect oil peroxidation leading to the development of new antioxidant technologies that helps to choose a suitable antioxidant to protect oil substrates against oxidation (Delfanian et al., 2016; Delfanian and Sahari, 2020).

Commercial vegetable oils usually contain $0.02-0.05 \%$ of water and various types of surface-active agents like phospholipids, free fatty acids (1.0-140 mmol/kg oil), sterols, mono- and/or diacylglycerols that during the refining process are not entirely removed. Bulk oils also including many other surface-active agents, e.g., hydroperoxides $(\mathrm{LOOH})$, ketones, aldehydes, and alcohols that are derived from lipid oxidation (Ghnimi et al., 2017). The water content increases with the decomposition of $\mathrm{LOOH}$ molecules during lipid oxidation. The LOOH molecules produced during peroxidation tends to entrap traces of water and form micelles beyond their critical reverse micelle concentration (CMC). Reverse micelles are generally organized when transferred lipid oxidation from the initiation to the propagation phase. The number and size of reverse micelles increased with the increasing water content and the surfactant molecules as lipid peroxidation progresses. This can change the structure and properties of $\mathrm{LOOH}$ reverse micelles. Reverse micelles are structurally containing a water core stabilized by surfactants molecules with nonpolar tails of the surfactant extending into the oil phase and the polar head groups extending into the water core. Reverse micelles are efficient nano-reactors that significantly alter the chemical reaction rates between water- and oil-soluble components by creating a water-oil interface (Budilarto and Kamal-Eldin, 2015b).

Recent studies have shown that the water-oil interfaces created by reverse micelles are the actual oxidation site in bulk phase oils. Antioxidant molecules positioning their polar head groups and nonpolar tails at the water-oil interfaces and improved the oxidative stability of bulk oils by stabilizes reverse micelles as well as by scavenging radicals at the interfaces (Kittipongpittaya et al., 2014; Lehtinen et al., 2017; Mansouri et al., 2020). Therefore, antioxidant efficiency in lipid systems is attributed to its innate capacity as a chelating agent or radical scavenger, interaction with other reactants, and locating into the water-oil interface (Chaiyasit et al., 2007).

In the literature, studies on the homologous series of antioxidants revealed the nonlinear behavior or cut-off effect for lipophilic antioxidants (alkyl esters derivatives of phenols) in the lipid system; antioxidant activity enhances as the length of the alkyl chain is reached until a critical chain length, after which further chain length extension causes a drastic decrease in antioxidant activity (da Silveira et al., 2020; Kikuzaki et al., 
2002; Sørensen et al., 2015). The nonlinear behavior of lipophilic antioxidants relates to their location, partitioning, and mobility in the bulk oil affected by molecular size and polarity. Therefore, despite the number of hydroxyl groups $(-\mathrm{OH})$, the antiradical capacity of phenolic antioxidants is also related to the number of carbon atoms in the alkyl chain (Shahidi and Zhong, 2011).

Gallic acid (3,4,5-trihydroxybenzoic acid) and its alkyl ester derivatives, including methyl, propyl, octyl, dodecyl, and stearyl gallates, have been recognized as natural antioxidants with unique biological activities. In recent years, a limited number of studies have examined the antiradical potency of gallic acid alkyl ester derivatives in chemical and biological systems (Kikuzaki et al., 2002; Lu et al., 2006). However, concerning the interfacial phenomena, there is no reported data on the effect of steric structure on interfacial performance and mechanism action of gallic acid alkyl ester derivatives in bulk phase oil.

Therefore, in this paper, the effect of length of alkyl chain on the interfacial activity of gallic acid alkyl ester derivatives in bulk phase oil was evaluated that is expected to impact the colloidal changes of bulk oil during lipid peroxidation.

\section{Materials and Methods}

\section{Chemicals}

The refined soybean seed oil was obtained by a local oil refining factory (Aliagolestan Co., Gorgan, Iran). Antioxidant compounds including gallic acid, methyl gallate, propyl gallate, octyl gallate, dodecyl gallate, and stearyl gallate of analytical grade (Fig. 1) were supplied from Sigma-Aldrich (St. Louis, MO). All the other solvents and chemicals applied in this research were purchased from Sigma-Aldrich (St. Louis, MO) and Merck (Darmstadt, Germany).

\section{DPPH Free Radical Assay}

The anti-DPPH* activity of antioxidant compounds was examined according to the method developed by Delfanian et al. (2015). Briefly, $100 \mu \mathrm{L}$ of antioxidant solutions (10-50 $\mu \mathrm{M})$ was added to $3 \mathrm{~mL}$ of methanolic solution of $\mathrm{DPPH}^{*}()$. The absorbance of solution $\left(\mathrm{A}_{\text {sample }}\right)$ was read at $517 \mathrm{~nm}$ against a blank $\left(\mathrm{A}_{\text {control }}\right)$ after 30 min incubation at The ability of phenolic antioxidants in radical scavenging (\%) was investigated from Eq. (1):

$\% R S A=\frac{A_{\text {control }}-A_{\text {sample }}}{A_{\text {control }}} \times 100(1)$

The $\mathrm{IC}_{50},[\mathrm{AH}]$ required to scavenge $50 \%$ of $\mathrm{DPPH}^{*}$, was determined by interpolating the linear regression analysis.

\section{$\mathrm{B}-\alpha \ddot{\rho} о \tau \varepsilon \nu \varepsilon \mathrm{B} \lambda \varepsilon \alpha \varsigma \eta\llcorner\gamma \mathrm{M} \varepsilon \tau \eta \delta \delta$}

Briefly, $0.2 \mathrm{mg}$ of the $\beta$-carotene was dissolved in $10 \mathrm{~mL}$ of chloroform to prepare $\mathbf{t}$ he $\beta$-carotene solution. Then, $20 \mathrm{mg}$ linoleic acid and $200 \mathrm{mg}$ Tween 40 were added to $1 \mathrm{~mL}$ of $\beta$-carotene solution. After evaporation of chloroform, $50 \mathrm{~mL}$ of oxygenated distilled water was added to the mixture by vigorous shaking. Finally, $100 \mu \mathrm{L}$ of antioxidant compounds was added to $4 \mathrm{~mL}$ of the prepared emulsion. The emulsion absorbance was recorded at $470 \mathrm{~nm}$ immediately at $\mathrm{t}=0 \mathrm{~min}$. The emulsion vial was stored in a water bath at 45 ${ }^{\circ} \mathrm{C}$ for $35 \mathrm{~min}$, and finally, the emulsion absorbance was recorded (Shahsavari et al., 2008). The percentage inhibition (\%I) was calculated from Eq. (2):

$\% I=\frac{A_{S(t)}-A_{C(t)}}{A_{C(0)}-A_{C(t)}} \times 100(2)$

where $A_{C(t)}$ and $A_{S(t)}$ are the absorbance of the control and sample at $t=30$ min, respectively, and $A_{C(0)}$ is the control absorbance at $\mathrm{t}=0 \mathrm{~min}$.

\section{Oxidative Stability Test}

Gallic acid and alkyl gallates at a concentration of $1.2 \mathrm{mM}$ were added to $3 \mathrm{~g}$ of stripped soybean oil. Rancimat (Metrohm 743, Herisau, Switzerland) test was performed at $120^{\circ} \mathrm{C}$ with a $15 \mathrm{~L} / \mathrm{h}$ airflow rate to 
measure oxidative stability index (OSI) (Delfanian et al., 2015).

\section{Partition Coefficient $(\log \mathrm{P})$}

The antioxidants solution in 1-octanol $(3 \mathrm{mM})$ was stored for one hour at $60{ }^{\circ} \mathrm{C}$. Then, the maximum solution absorbance was determined immediately by the UV spectrum $\left(\mathrm{A}_{0}\right)$. Five milliliters of acetate buffer $(0.1 \mathrm{M}$, $\mathrm{pH}$ 5.5) was added to $5 \mathrm{~mL}$ of the above solutions and vortexed for $1 \mathrm{~min}$. Finally, the maximum absorbance of the octanol layer (Ax) was measured after 30 min (Gordon et al., 2001). Partition coefficient was calculated from Eq. (3):

$\log P=\log \left(\frac{A_{X}}{A_{0}-A_{X}}\right)$

\section{Soybean Oil Purification}

Purification of soybean oil was performed according to the chromatographic method developed by Yoshida et al. (1992) with a chromatographic glass column $(36 \times 3.4 \mathrm{~cm}$ I.D.) packed with aluminum oxide 60 (activated for $3 \mathrm{~h}$ at $200{ }^{\circ} \mathrm{C}$ ) with a ratio of 1 (oil) to 1 (absorbent). As a final step, the amount of tocopherols (Wong et al., 1988), total phenols (Capannesi et al., 2000), and hydroperoxides were determined to ensure the purification process efficiency. The purified soybean oil triacylglycerols were contained inconsiderable values of PV $(<1 \mathrm{meq} / \mathrm{kg})$, phenols and tocopherols $(<1 \mathrm{mg} / \mathrm{kg})$.

\section{Fatty Acid Composition}

The fatty acids profile of soybean oil was determined by converting fatty acids into their methyl esters (FAMEs). In brief, $0.3 \mathrm{~g}$ of oil samples were added to $7 \mathrm{~mL}$ of hexane and then methylated with $2 \mathrm{~mL}$ of methanolic potassium hydroxide solution $(7 \mathrm{~N})$ for $10 \mathrm{~min}$ at $50{ }^{\circ} \mathrm{C}$. The gas-liquid chromatography (GC, HP-5890, Hewlett-Packard, CA, USA) equipped with a flame ionization detector (FID) was employed to identify FAMEs. The capillary column used was CP-FIL 88 (Suppl Co., Inc., Bellefonte, PA, USA). The flow rate of carrier gas (nitrogen) was $0.75 \mathrm{~mL} / \mathrm{min}$. The temperature of both injector and detector was kept at $250{ }^{\circ} \mathrm{C}$, and that of the oven at $198{ }^{\circ} \mathrm{C}$. The composition of fatty acids was calculated in relative area percentages (Fatemi and Hammond, 1980).

\section{Peroxide Value (PV)}

In brief, the oil treatments (0.001-0.3 g) were diluted in chloroform-methanol $(9.8 \mathrm{~mL}, 7: 3 \mathrm{v} / \mathrm{v})$. Then, 50 $\mu \mathrm{L}$ of the clear solution of iron (II) chloride, and $50 \mu \mathrm{L}$ ammonium thiocyanate solution $(30 \% \mathrm{w} / \mathrm{v})$ were added on a vortex mixer for $5 \mathrm{~s}$. The solution was saved for 5 min at $25{ }^{\circ} \mathrm{C}$, and then the absorbance of the solution was measured at $500 \mathrm{~nm}$ (Shantha and Decker, 1994).

\section{Preparation of Oxidizing Systems}

The soybean oil triacylglycerols (TAGs) $(28.5 \mathrm{~g}$ ) treatment with $1.2 \mathrm{mmol}$ of gallic acid and alkyl gallates stored in a Petri dish with a diameter of $19.5 \mathrm{~cm}$ in a 1-mm layer (kinetic regime) and then oxidized in accelerated oil oxidation at $60{ }^{\circ} \mathrm{C}$.

\section{Kinetic Parameters}

The combinational kinetic model described by Farhoosh (2018) was used to determine the PV-based kinetic parameters. The kinetic curve of the accumulation of $\mathrm{LOOH}$ molecules was drawn by plotting $\mathrm{PV}$ changes over time (Fig. 2). IP (Eq. (4)) and CMC (Eq. (5)) of LOOH was calculated from the $\mathrm{x}$ - and y-coordinates of the intersection point of two straight lines fitted on the initiation and propagation stages of the kinetic curves, respectively. The second straight line precisely arose from the sigmoidal kinetic model (Eq. (6)) fitted on the whole range of $\mathrm{PV}$ changes over time.

$\mathrm{IP}=\frac{K_{1}\left(2-K_{1} C_{c}+\ln K_{2}\right)-4 \mathrm{PV}_{0} K_{2}}{4 K_{i} K_{2}-k_{1}^{2}}(4)$

$C M C=K_{i}(\mathrm{IP})+\mathrm{PV}_{0}(5)$

$\mathrm{PV}=\frac{K_{1}}{\exp \left[K_{1}\left(C_{c}-t\right)\right]+K_{2}}(6)$ 
where $\mathrm{k}_{\mathrm{i}}\left(\right.$ meq $\left.\mathrm{kg}^{-1} \mathrm{~h}^{-1}\right), \mathrm{k}_{1}\left(\mathrm{~h}^{-1}\right)$ and $\mathrm{k}_{2}\left(\mathrm{~kg} \mathrm{meq}^{-1} \mathrm{~h}^{-1}\right)$ are the parameters of the equations; $\mathrm{C}_{\mathrm{c}}\left(\mathrm{kg}\right.$ meq $\left.^{-1}\right)$ is an integration constant and $\mathrm{PV}_{0}\left(\right.$ meq $\left.\mathrm{kg}^{-1}\right)$ is $\mathrm{PV}$ at $\mathrm{t}=0$.

Antioxidative activities of alkyl gallate and gallic acid in bulk oil peroxidation were examined by effectiveness factor $(F)$, oxidation rate ratio (ORR), antioxidant activity $(A)$, and mean rate of antiradical consumption $\left(W_{\mathrm{AH}}\right)$.

Stabilization factor $(F)$ or antioxidant efficiency, which showing the potency of an antioxidant (AH) in delaying oxidation, was calculated by Eq. (7).

$F=\frac{\mathrm{IP}_{\mathrm{AH}}}{\mathrm{IP}_{0}}(7)$

where $\mathrm{IP}_{0}$ and $\mathrm{IP}_{\mathrm{AH}}$ are the IP in the absence and presence of phenols, respectively.

The parameter ORR, which is inversely related to antioxidant power, was determined by Eq. (8).

ORR $=\frac{K_{i}}{K_{i 0}}(8)$

where $K_{i}$ and $K_{i 0}$ are the pseudo-zero order rate constants in the presence and absence of phenolic antioxidants, respectively.

Antioxidant activity $(A)$ was obtained with Eq. (9).

$A=\frac{F}{\mathrm{ORR}}(9)$

The parameter $W_{\mathrm{AH}}$, the average rate of $\mathrm{AH}$ consumption, was calculated by Eq. (10) (Marinova and Yanishlieva, 2003).

$W_{\mathrm{AH}}=\frac{[\mathrm{AH}]_{0}}{\mathrm{IP}_{\mathrm{AH}}}(10)$

\section{P-Anisidine Value}

The AOCS Official Method was used to determine $p$-anisidine values of oil samples (Society and Firestone, 1994). Briefly, $0.2 \mathrm{~g}$ of the oil sample $(\mathrm{m})$ was mixed with $23 \mathrm{ml}$ of iso-octane, and then its adsorption $\left(\mathrm{A}_{\mathrm{b}}\right)$ was determined at $350 \mathrm{~nm}$. Then $5 \mathrm{ml}$ of this solution was added to $1 \mathrm{~mL} p$-anisidine reagent (25\% in glacial acetic acid). The mixture absorbance $\left(\mathrm{A}_{\mathrm{s}}\right)$ was read at $350 \mathrm{~nm}$ after $10 \mathrm{~min}$ stored in the dark at $25 \operatorname{degC}$. The $p$-anisidine value was determined by Eq. (11).

$\mathrm{AV}=25(1 / 2 \mathrm{As}-\mathrm{Ab}) / \mathrm{m}(11)$

\section{Water Content Analysis}

The water content changes in the oil samples during lipid peroxidation were determined by Karl Fischer titrator (684 KF Coulometer, Metrohm, Germany). The quantitative determination of the water content of the sample is based on the fact that a given amount of substance $\mathrm{I}_{2}$ leads to the conversion of an equivalent amount of substance $\mathrm{H}_{2} \mathrm{O}$ in the vicinity of methanol and sulfur dioxide. Therefore, by determining the amount of $\mathrm{I}_{2}$ consumed in the reaction, the amount of $\mathrm{H}_{2} \mathrm{O}$ is determined electrochemically. Briefly, the oil samples $(0.1 \mathrm{~g})$ were placed into a cell containing a mixture of chloroform/methanol 70:30 and a reagent of Karl Fischer (CombiCoulomat fritless) (Felgner et al., 2008).

\section{Interfacial Tension Analysis}

An optical contact angle instrument (OCA20, Data physics, Germany) with the pendant drop method was employed to measure oil-water interfacial tension at $25 \mathrm{degC}$ (Morita et al., 2002).

\section{Micelle Size Analysis}

A dynamic light scattering instrument (Brookhaven NanoBrook 90Plus Zeta instrument, USA) was used to monitor the micelle size changes in the oil sample during lipid peroxidation (Budilarto and Kamal-Eldin, 2015b). The micelle size distribution graph of the oil sample (2 mL) (intensity, \%, versus diameter, nm) was 
determined at the angle of 90deg at $25 \mathrm{degC}$. The refractive index and viscosity of soybean oil were 1.418 +- 0.01 and 0.047 +- $0.001 \mathrm{~Pa} \mathrm{~s}$, respectively.

\section{Statistical Analysis}

Each analysis was done in triplicate, and one-way ANOVA was used for the analysis of obtained data. For the determination of significant differences of means at $P<0.05$ Duncan's multiple range tests were used. Regression analyses and ANOVA were performed using SlideWrite 7.01, Excel, and SPSS Statistics 19 software.

\section{Results and Discussion}

\section{Soybean Oil Characterization}

The chemical properties of the purified and unpurified soybean oils are shown in Table 1. As can be seen, the purification process did not affect the composition of soybean oil fatty acids. The stripped soybean oil contained an insignificant amount of hydroperoxides, phenolic compounds, and tocopherols, showing the minor components' efficient removal that may interfere with the antioxidant compounds.

\section{Antioxidant Activity in Various Oxidative Environments}

In this section, the antiradical capacities of alkyl gallates and gallic acid were examined using different chemical methods: $\beta$-carotene bleaching, $\mathrm{DPPH}^{*}$ scavenging, and Rancimat assays. These assays were carried to evaluate the impact of $-\mathrm{COOH}$ group and the ester chain length on the antioxidative activity of gallic acid derivatives in various oxidative environments.

The ability of antioxidative compounds for scavenging DPPH free radicals is presented in Table 2. The antiradical activities of gallic acid and alkyl gallates enhanced as the antioxidant concentrations increased from 10 to $50 \mu \mathrm{M}$. The percent values of for gallic acid at all concentrations were significantly higher than the alkyl gallates. Considering the $\mathrm{IC}_{50}$, the gallic acid concentration required to scavenge $50 \%$ of $\mathrm{DPPH}^{*}$ was considerably lower than its alkyl ester derivatives. These results were in accordance with Asnaashari et al. (2019) and Mansouri et al. (2020) that reported the anti-DPPH* activity of gallic acid was significantly more potent compared to methyl gallates.

The O-H bond disassociation enthalpy (O-H BDE), intramolecular hydrogen bonds (IHB), and ionization potential are the three critical parameters that affect the antiradical activity of antioxidant agents. Given that the O-H BDE, IHB, and ionization potential of alkyl gallates are similar, thus the steric impact can be a plausible explanation for the difference in antiradical activity of alkyl gallates. The ester structure affects the polarity and solubility of antioxidant compounds as well as their molecular mobility and availability to oxidative components ( $\mathrm{Lu}$ et al., 2006). Our results showed that the radical scavenging potency of gallic acid as affected by an extra carboxyl group than alkyl gallates. In fact, the dissociation possibility of the carboxyl group in polar media is the main reason for increased the electron-donating and H-atom transfer activities of gallic acid than the alkyl gallates. In contrast to the electron-donating impact of carboxylate anion, $-\mathrm{COOH}$ is considered an electron-withdrawing group that increases the O-H BDE of the phenolic ring (Correia et al., 2004). As can be seen in Table 2, the polarity ( $\log \mathrm{P}$ ) of gallic acid was significantly higher than the alkyl gallates, which is leading to more hydrophilic interactions between the antioxidant and the polar molecules of methanol as a reaction solvent.

In the $\beta$-carotene bleaching assay, gallic acid and alkyl gallates prevented the extent of $\beta$-carotene bleaching by neutralizing the linoleate-free radical and other free radicals formed in the emulsion. As shown in Table 2 , a concentration-dependent antioxidant potential was observed for all antioxidant components studied. A comparison of antioxidant capacity in the emulsion system showed that gallic acid was the lowest reactive antioxidant than alkyl gallates. So that, the $\mathrm{IC}_{50}$ value of antioxidant agents was as follows: dodecyl gallate $<$ octyl gallate $<$ propyl gallate methyl gallate $<$ gallic acid $<$ stearyl gallate. This means that the alkyl gallates concentration required for scavenging $\% 50$ of linoleate-free radicals was significantly lower than the gallic acid. In general, due to the appropriate length of the alkyl chain, dodecyl gallate had a more effective 
interfacial performance at the water-oil interfaces. The nonlinear behavior or cut-off effect was observed for inhibitory activities of homologous series of antioxidative compounds in the $\mathrm{W} / \mathrm{O}$ emulsion. The interfacial activities of gallic acid derivatives enhanced as the lengths of the alkyl chain were reached until a critical chain length (12 carbon atoms); after that, further chain length extension causes a decrease in antioxidant activities. Medina et al. (2009), Laguerre et al. (2010) and Meireles et al. (2019) reported similar findings showing that the lipophilic esters with short medium-chain compared to long-chain esters improved the activity of antioxidative compounds in the multiphase system. Laguerre et al. (2009) also reported in the emulsified medium the antiradical potency enhances as the alkyl chain is lengthened, with a threshold for the dodecyl chain, after which further chain extension causes a drastic decrease in antiradical activity. The increased antiradical activities of the alkyl gallates in $\beta$-carotene-linoleic acid emulsion compared to gallic acid can be attributed to increased hydrophobicity $(\log \mathrm{P})$, surface-active characteristic, and the precise placement of antioxidants in the water-oil interface.

In the Rancimat test, the oxidative stability index (OSI) of stripped soybean oil (0.32 h) was significantly promoted with the antioxidants added. The OSI values of bulk soybean oil treatments with antioxidant agents were as follow: propyl gallate $>$ octyl gallate ${ }^{\sim}$ dodecyl gallate $>$ stearyl gallate ${ }^{\sim}$ methyl gallate $>$ gallic acid. A higher induction period was obtained for soybean oil containing propyl gallate compared to other antioxidants means that propyl gallate was the most effective antioxidant to increase oil oxidative stability at high temperature $\left(120^{\circ} \mathrm{C}\right)$. This result was in accordance with Phonsatta et al. (2017) that reported the OSI of bulk oil containing alkyl gallates, especially propyl gallate, was significantly more potent compared to gallic acid. Concerning the carboxyl group's electron-withdrawing character, which is not markedly dissociated in the hydrophobic media, gallic acid had the lowest inhibitory activity than alkyl gallates in the lipid system. Studies have shown that the esterification of gallic acid with fatty alcohols can be increasing its hydrophobicity as well as surface-active properties (Chaiyasit et al., 2005). According to log P results (Table 2 ) the hydrophobicity of alkyl gallates was higher than the gallic acid. Therefore, the increased antioxidant activities of the alkyl gallates, especially propyl gallate, in bulk phase oil compared to gallic acid can be attributed to improved amphiphilic properties by increasing the alkyl chain length and the precise placement of antioxidants in the actual site of oxidation. Our findings agreed with those reported by Kikuzaki et al. (2002). The results clearly showed the nonlinear antioxidative activities for alkyl gallates due to enhance in the length of the alkyl chain. The size of antioxidants affects their activity by changing their mobility in the bulk phase oils, leading to a cut-off effect. Lipophilic antioxidative components by long alkyl chains have lower mobility than those with a smaller size because of steric hindrance, so decreased diffusibility toward the reactive centers such as free radicals and oxidizable substrates. Furthermore, enhance in the length of the alkyl chain increase the possibility of hydrophobic interaction among antioxidative components and the environment such as the membrane or emulsifiers, which cause a decrease in mobility and diffusion of the antioxidative components to the oxidation site of bulk oil (Laguerre et al., 2015).

\section{Inhibited Bulk Oil Oxidation}

\section{Antioxidant Effect on Kinetic Parameters}

The peroxidation behavior of pure TAGs and TAGs containing $1.2 \mathrm{mM}$ of gallic acid and alkyl gallates at $60{ }^{\circ} \mathrm{C}$ are shown in Fig 2 and Fig 3. The TAGs were oxidized to the end of the termination phase to plot the kinetic curve of the $\mathrm{LOOH}$ accumulation accurately. The combinational kinetic model was fitted very well on the PVs changes over time and provided accurate kinetic parameters. The kinetic oxidation parameters representing the inhibitory effects of the antioxidant components in bulk oil are shown in Table 3. The oxidation rate of soybean oil TAGs $\left(K_{i}\right)$ was significantly reduced by adding gallic acid and alkyl gallates. Considering kinetic parameters $F$, ORR, and $A$, which is the ratio of $F$ to ORR, the greater extents of strength and effectiveness were observed for methyl gallate. The antioxidant consumption $W_{\mathrm{AH}}$ for TAGs containing methyl, propyl, and octyl gallates during lipid peroxidation was lower than gallic acid. In general, the results indicated that the esterification of gallic acid and the addition of carbon atoms to the alkyl chain $(<8)$ improved antioxidant capacity. Considering to higher value of $F$ and $A$, and the lower value of $O R R$ parameters, the inhibitory effects of antioxidant compounds in TAGs were as follows: methyl 
gallate $>$ propyl gallate $>$ octyl gallate $>$ gallic acid $>$ dodecyl gallate $>$ stearyl gallate. Comparison of the mechanism of antioxidant action of methyl gallate and gallic acid in bulk fish, canola, and olive oils showed that methyl gallate was the most effective antioxidant in preventing lipid oxidation (Mahdavianmehr et al., 2016). Although, in another study Mansouri et al. (2020) reported that the inhibitory activity of gallic acid in bulk sunflower oil was much better than methyl gallate.

As can be seen in Table 2, the hydrophobicity of alkyl gallates ( $\log \mathrm{P})$ was higher than the gallic acid. Therefore, the increased antioxidant potency of the methyl, propyl, and octyl gallates in bulk phase oil compared to gallic acid can be attributed to improve surface-active characteristics by the increase in the alkyl chain length and the precise placement of antioxidants in the actual site of oxidation. Lu et al. (2006) reported that the impact of alkyl gallates depends more on their molecular polarity and solubility that affect their availability to the reactive center. The nonlinear antioxidative activities were observed for alkyl gallates in bulk oil peroxidation. So that, the inhibitory activity of dodecyl gallate and stearyl gallate during lipid peroxidation was lower than the gallic acid. The size of antioxidants affects their activity by changing their mobility in the bulk phase oils, leading to a cut-off effect. Lipophilic antioxidative components by long alkyl chains have lower mobility, so decreased diffusibility toward the reactive centers. Moreover, the increase in the alkyl chain length enhances the possibility of hydrophobic interaction (Budilarto and Kamal-Eldin, 2015a).

Considering the mechanism of the free radical chain of bulk oil oxidation, antioxidant molecules of higher effectiveness take part more in chain termination reactions blocking peroxyl radicals (LOO* ) than in chain initiation reactions creating hydroperoxyl $\left(\mathrm{HOO}^{*}\right)$ and alkoxyl $\left(\mathrm{LO}^{*}\right)$ radicals. The higher potency indicates that the hydrogen-donating molecules $(\mathrm{AH})$ provide radicals $\left(\mathrm{A}^{*}\right)$ of less possibility to participate in chain propagation reactions producing reactive radicals, such as $\mathrm{LOO}^{*}, \mathrm{~L}^{*}$, and $\mathrm{AOO}^{*}$ (Marinova and Yanishlieva, 2003). Mechanistically, fewer tendencies were observed for methyl, propyl, and octyl gallates to participate in the side-chain reactions (data not shown). While the participation of gallic acid and stearyl gallate in the side-chain reactions were much higher than other antioxidant compounds, which is the main reason for the poorer performance of gallic acid and stearyl gallate compared to other phenolic antioxidants in lipid systems.

CMC's kinetic parameter marks the transition from the initiation stage where micelles are stable to the propagation stage with extensive micellar collisions. The CMC provides a logical explanation regarding the interfacial performance of alkyl gallates in protecting the oils from peroxidation. The addition of antioxidant compounds decreased the CMC value of the oil samples (Table 3). This denotes that free LOOH molecules are present in lower concentrations in the reaction medium and organized as more stable reverse micelles by the antioxidant molecules at the water-oil interfaces. In this respect, the analyses of micelle size and interfacial tension provided helpful evidence.

\section{Interfacial Performance in Supramolecular Oxidation}

According to the association colloids hypothesis, reverse micelles are efficient nano-reactors that significantly alter the chemical reaction rate between water- and oil-soluble components by creating the water-oil interface. The LOOH molecules are surface-active and tend to migrate to the water-oil interface of reverse micelles. Therefore, the accessibility of surface-active phenolic antioxidants to reactive free radicals increases with partitioning at the water-oil interface created by reverse micelles (Chen et al., 2010).

As shown in Table 4, the water content in the oil treatments increased during the oxidation steps (0.02-0.1\%). The increase in water content is due to the decomposition of $\mathrm{LOOH}$ molecules during lipid peroxidation. In the initiation phase, $\mathrm{LOOH}$ molecules take part in the monomolecular decomposition reactions ( $\mathrm{LOOH}+$ $\mathrm{LH} \rightarrow \mathrm{LO}^{*}+\mathrm{L}^{*}+\mathrm{H}_{2} \mathrm{O}$ ), while in the propagation phase, extensive micelle collisions increase the bimolecular decomposition reaction of $\mathrm{LOOH}\left(2 \mathrm{LO}_{2} \mathrm{H} \rightarrow \mathrm{LO}_{2}{ }^{*}+\mathrm{LO}^{*}+\mathrm{H}_{2} \mathrm{O}\right)$ (Budilarto and Kamal-Eldin, 2015a). The LOOH reverse micelles size, and interfacial tension increased in parallel with the increase amount of water during lipid oxidation phases. As the amount of water and $\mathrm{LOOH}$ molecules increases, the reverse micelles grow in size and number until their concentration is high enough to flocculate as mesophases, which 
are then disintegrated and decomposed to form a range of secondary oxidation products in the final oxidation steps (Budilarto and Kamal-Eldin, 2015b).

As can be seen in Table 4, with increasing of LOOH molecules, the interfacial tension of purified soybean oil decreased from 36.02 to $33.26 \mathrm{mN} / \mathrm{m}$ at the induction period (IP), then decreased from 33.26 to $30.19 \mathrm{mN} / \mathrm{m}$ at $\mathrm{IP}_{\mathrm{m}}$ due to the intensification of the production of $\mathrm{LOOH}$ which are incorporated into the reverse micelles. Finally, the interfacial tension at $\mathrm{P}_{\mathrm{e}}$ decreased from 30.19 to $24.71 \mathrm{mN} / \mathrm{m}$ due to the flocculates breakdown that causing to release of $\mathrm{LOOH}$ molecules along with numerous secondary oxidation products. The addition of phenolic antioxidants was significantly decreased the interfacial tension of bulk oils. Due to the effect of steric structure on amphiphilic properties, the levels of interfacial tension at $t=0$ in bulk oils containing gallic acid alkyl ester derivatives were lower than the gallic acid. After that, the values were more steeply increased in parallel with the progress of lipid oxidation. The results clearly showed that esterification with the aim of increasing the alkyl chain length had a nonlinear impact on the amphiphilic property of alkyl gallates, which was in agreement with Elder et al. (). The significantly increased levels of interfacial tension in the presence of phenolic antioxidants, causing to the formation of mixed reverse micelles of a quite larger droplet size compared to the reverse micelles only consisting of $\mathrm{LOOH}$ molecules, which was in accordance with the results reported by Mansouri et al. (2020). The quite higher interfacial tension for methyl gallate at IP can also confirm its higher ability in packing the free LOOH molecules as organized reveres micelles. Furthermore, the soybean oil containing methyl gallate had lower values of the CMC and larger micellar size, which confirms the methyl gallate, could more effectively decrease the concentration of free LOOH molecules and inhibit them in an interfacial way.

As shown in Table 4, the $p$-anisidine value (AV), which is a useful index for measuring secondary oxidation products, in all of the oil samples increased during initiation and propagation stages much more slowly than the LOOH. The protective impact of alkyl gallates except dodecyl and stearyl gallates against the production of carbonyl compounds was much better than the gallic acid.

In general, considering the water content, micellar size, and interfacial tension results, the antiradical potency of the phenolic inhibitors was significantly promoted by increasing the length of the alkyl chain (until a critical chain length) due to the increased interfacial activity. The interfacial performance of antioxidative compounds in supramolecular oxidation of bulk oil was in the order of methyl gallate $>$ propyl gallate $>$ octyl gallate $>$ gallic acid $>$ dodecyl gallate $>$ stearyl gallate, which was completely in line with the values of the AV, CMC (Table 3), and the corresponding physical parameters shown in Table 4. The reason that methyl, propyl, and octyl gallates (hydrophobic antioxidants) were more effective than gallic acid (hydrophilic antioxidant) in bulk oil could be due to their increased partitioning at the water-oil interface created by reverse micelles and, thereby, increasing the accessibility of antioxidative compounds to reactive free radicals.

\section{Conclusions}

In this study, we investigated the physicochemical changes of LOOH molecules during bulk oil peroxidation. The hydroperoxide molecules are surface-active agents that in the presence of the enhancing water content during oxidation decrease the interfacial tension of peroxidized bulk oils. Our results indicated that hydroperoxide molecules during oxidation form reverse micelles that after the induction period grow in size and number, causing the flocculation of hydroperoxide reverse micelles that are disintegrated and decomposed into secondary oxidation products in the propagation phase. Therefore, the addition of any antioxidant agents of surface-active can impact the behavior of hydroperoxide molecules and their catalytic roles. Hence, the effect of alkyl chain length on surface-active properties as well as the interfacial performance of gallic acid ester derivatives in peroxidized bulk oil was evaluated through physicochemical analysis. Our findings showed that the addition of gallic acid ester derivatives, especially methyl gallate, were decreased hydroperoxides molecule concentration in the reaction medium and also reduced their oxidative collisions. Thus, the esterification of phenolic agents with optimum alkyl chain length can maximize exploitation of innate activities of antioxidative compounds by suitable partitioning into the water-oil interfaces and better packing of hydroperoxide molecules at interfacial way. 


\section{Conflict of Interest}

The authors report no conflict of interest.

\section{References}

Asnaashari, M., Farhoosh, R., \& Farahmandfar, R. (2019) Preservation of gallic acid and methyl gallate on purified Kilka fish oil oxidation by Rancimat. Food Science $\mathcal{E}$ Nutrition, 7 (12):4007-4013.

Budilarto, E. S., \& Kamal-Eldin, A. (2015a) The supramolecular chemistry of lipid oxidation and antioxidation in bulk oils. European Journal of Lipid Science and Technology, 117 (8):1095-1137.

Budilarto, E. S., \& Kamal-Eldin, A. (2015b) Water content and micelle size change during oxidation of sunflower and canola oils. European Journal of Lipid Science and Technology, 117 (12):1971-1977.

Capannesi, C., Palchetti, I., Mascini, M., \& Parenti, A. (2000) Electrochemical sensor and biosensor for polyphenols detection in olive oils. Food Chemistry,71 (4):553-562.

Chaiyasit, W., Elias, R. J., McClements, D. J., \& Decker, E. A. (2007) Role of physical structures in bulk oils on lipid oxidation. Critical Reviews in Food Science and Nutrition, 47 (3):299-317.

Chaiyasit, W., McClements, D. J., \& Decker, E. A. (2005) The relationship between the physicochemical properties of antioxidants and their ability to inhibit lipid oxidation in bulk oil and oil-in-water emulsions. Journal of Agricultural and Food Chemistry, 53 (12):4982-4988.

Chen, B., Han, A., McClements, D. J., \& Decker, E. A. (2010) Physical structures in soybean oil and their impact on lipid oxidation. Journal of Agricultural and Food Chemistry, 58 (22):11993-11999.

Correia, C. F., Guedes, R. C., dos Santos, R. M. B., Cabral, B. J. C., \& Simoes, J. A. M. (2004) O-H Bond dissociation enthalpies in hydroxyphenols. A time-resolved photoacoustic calorimetry and quantum chemistry study. Physical Chemistry Chemical Physics, 6 (9):2109-2118.

da Silveira, T. F. F., Cajaiba, L. M., Valentin, L., Barea, B., Villeneuve, P., \& Castro, I. A. (2020) Effect of sinapic acid ester derivatives on the oxidative stability of omega-3 fatty acids rich oil-in-water emulsions. Food Chemistry,309:125586.

Delfanian, M., Kenari, R. E., \& Sahari, M. A. (2015) Antioxidant activity of loquat (Eriobotrya japonica Lindl.) fruit peel and pulp extracts in stabilization of soybean oil during storage conditions. International Journal of Food Properties, 18 (12):2813-2824.

Delfanian, M., Kenari, R. E., \& Sahari, M. A. (2016) Evaluation of antioxidant activity of loquat fruit (Eriobotrya japonica lindl.) skin and the feasibility of their application to improve the oxidative stability of soybean oil.Journal of Food Science and Technology, 53 (5):2244-2252.

Delfanian, M., \& Sahari, M. A. (2020) Improving functionality, bioavailability, nutraceutical and sensory attributes of fortified foods using phenolics-loaded nanocarriers as natural ingredients. Food Research International :109555.

Elder, A. S., Coupland, J. N., \& Elias, R. J. Effect of alkyl chain length on the antioxidant activity of alkylresorcinol homologues in bulk oils and oil-in-water emulsions. Food Chemistry, 346 :128885.

Farhoosh, R. (2018) Reliable determination of the induction period and critical reverse micelle concentration of lipid hydroperoxides exploiting a model composed of pseudo-first and-second order reaction kinetics. LWT,98:406-410.

Fatemi, S. H., \& Hammond, E. G. (1980) Analysis of oleate, linoleate and linolenate hydroperoxides in oxidized ester mixtures. Lipids, 15 (5):379-385.

Felgner, A., Schlink, R., Kirschenbuhler, P., Faas, B., \& Isengard, H. D. (2008) Automated Karl Fischer titration for liquid samples-Water determination in edible oils. Food Chemistry, 106 (4):1379-1384. 
Ghnimi, S., Budilarto, E., \& Kamal-Eldin, A. (2017) The new paradigm for lipid oxidation and insights to microencapsulation of Omega-3 fatty acids. Comprehensive Reviews in Food Science and Food Safety, 16 (6):1206-1218.

Gordon, M. H., Paiva-Martins, F., \& Almeida, M. (2001) Antioxidant activity of hydroxytyrosol acetate compared with that of other olive oil polyphenols. Journal of Agricultural and Food Chemistry, 49 (5):24802485 .

Kikuzaki, H., Hisamoto, M., Hirose, K., Akiyama, K., \& Taniguchi, H. (2002) Antioxidant properties of ferulic acid and its related compounds. Journal of Agricultural and Food Chemistry, 50 (7):2161-2168.

Kittipongpittaya, K., Panya, A., McClements, D. J., \& Decker, E. A. (2014) Impact of free fatty acids and phospholipids on reverse micelles formation and lipid oxidation in bulk oil. Journal of the American Oil Chemists' Society,91 (3):453-462.

Laguerre, M., Bayrasy, C., Panya, A., Weiss, J., McClements, D. J., Lecomte, J., Decker, E. A., \& Villeneuve, P. (2015) What makes good antioxidants in lipid-based systems? The next theories beyond the polar paradox. Critical Reviews in Food Science and Nutrition, 55 (2):183-201.

Laguerre, M., Lopez Giraldo, L. J., Lecomte, J., Figueroa-Espinoza, M.-C., Barea, B., Weiss, J., Decker, E. A., \& Villeneuve, P. (2010) Relationship between hydrophobicity and antioxidant ability of "phenolipids" in emulsion: a parabolic effect of the chain length of rosmarinate esters. Journal of Agricultural and Food Chemistry, $\mathbf{5 8}$ (5):2869-2876.

Laguerre, M., Lopez Giraldo, L. J., Lecomte, J., Figueroa-Espinoza, M.-C., Baréa, B., Weiss, J., Decker, E. A., \& Villeneuve, P. (2009) Chain length affects antioxidant properties of chlorogenate esters in emulsion: the cutoff theory behind the polar paradox. Journal of Agricultural and Food Chemistry,57 (23):11335-11342.

Lehtinen, O.-P., Nugroho, R. W. N., Lehtimaa, T., Vierros, S., Hiekkataipale, P., Ruokolainen, J., Sammalkorpi, M., \& Österberg, M. (2017) Effect of temperature, water content and free fatty acid on reverse micelle formation of phospholipids in vegetable oil. Colloids and Surfaces B: Biointerfaces, 160 :355-363.

Lu, Z., Nie, G., Belton, P. S., Tang, H., \& Zhao, B. (2006) Structure-activity relationship analysis of antioxidant ability and neuroprotective effect of gallic acid derivatives. Neurochemistry International,48 (4):263-274.

Mahdavianmehr, H., Farhoosh, R., \& Sharif, A. (2016) Mechanism of the inhibitory effect of hydroxytyrosol on lipid oxidation in different bulk oil systems. Journal of the American Oil Chemists' Society, 93 (9):12331242 .

Mansouri, H., Farhoosh, R., \& Rezaie, M. (2020) Interfacial performance of gallic acid and methyl gallate accompanied by lecithin in inhibiting bulk phase oil peroxidation. Food Chemistry :127128.

Marinova, E. M., \& Yanishlieva, N. V. (2003) Antioxidant activity and mechanism of action of some phenolic acids at ambient and high temperatures. Food Chemistry,81 (2):189-197.

Medina, I., Lois, S., Alcántara, D., Lucas, R., \& Morales, J. C. (2009) Effect of lipophilization of hydroxytyrosol on its antioxidant activity in fish oils and fish oil-in-water emulsions. Journal of Agricultural and Food Chemistry, 57 (20):9773-9779.

Meireles, M., Losada-Barreiro, S., Costa, M., Paiva-Martins, F., Bravo-Diaz, C., \& Monteiro, L. S. (2019) Control of antioxidant efficiency of chlorogenates in emulsions: modulation of antioxidant interfacial concentrations. Journal of the Science of Food and Agriculture, 99 (8):3917-3925.

Morita, A., Carastan, D., \& Demarquette, N. (2002) Influence of drop volume on surface tension evaluated using the pendant drop method. Colloid and Polymer Science, 280 (9):857-864.

Phonsatta, N., Deetae, P., Luangpituksa, P., Grajeda-Iglesias, C., Figueroa-Espinoza, M. C., Le Comte, J. r. m., Villeneuve, P., Decker, E. A., Visessanguan, W., \& Panya, A. (2017) Comparison of antioxidant 
evaluation assays for investigating antioxidative activity of gallic acid and its alkyl esters in different food matrices. Journal of Agricultural and Food Chemistry, 65 (34):7509-7518.

Shahidi, F., \& Zhong, Y. (2011) Revisiting the polar paradox theory: a critical overview. Journal of Agricultural and Food Chemistry, 59 (8):3499-3504.

Shahsavari, N., Barzegar, M., Sahari, M. A., \& Naghdibadi, H. (2008) Antioxidant activity and chemical characterization of essential oil of Bunium persicum. Plant Foods for Human Nutrition, 63 (4):183-188.

Shantha, N. C., \& Decker, E. A. (1994) Rapid, sensitive, iron-based spectrophotometric methods for determination of peroxide values of food lipids. Journal of AOAC International, 77 (2):421-424.

Society, A. O. C., \& Firestone, D. (1994). Official methods and recommended practices of the American Oil Chemists' Society : AOCS press.

Sorensen, A.-D. M., Lyneborg, K. S., Villeneuve, P., \& Jacobsen, C. (2015) Alkyl chain length impacts the antioxidative effect of lipophilized ferulic acid in fish oil enriched milk. Journal of Functional Foods, 18 :959-967.

Wong, M., Timms, R., \& Goh, E. (1988) Colorimetric determination of total tocopherols in palm oil, olein and stearin. Journal of the American oil chemists society, 65 (2):258.

Yoshida, H., Kondo, I., \& Kajimoto, G. (1992) Participation of free fatty acids in the oxidation of purified soybean oil during microwave heating. Journal of the American Oil Chemists' Society, 69 (11):1136-1140.

\section{Figure captions}

Fig. 1 Molecular structure of gallic acid and alkyl gallates

Fig. 2 Schematic kinetic curve of the accumulation of LOOH during peroxidation. IP: induction period; CMC: critical reverse micelle concentration of $\mathrm{LOOH} ; \mathrm{P}_{\mathrm{m}}$ : the middle point of the propagation phase; $\mathrm{P}_{\mathrm{e}}$ : the end point of the propagation phase.

Fig. 3 The peroxide value changes in bulk soybean oils containing of gallic acid and alkyl gallates during lipid peroxidation at $60 \operatorname{deg} \mathrm{C}$

Table 1Chemical characteristics of the soybean oils before and after purification ${ }^{\text {a }}$

\begin{tabular}{lll}
\hline Parameter & Purification & Purification \\
\hline & Before & After \\
Fatty acids $(\% \mathrm{w} / \mathrm{w})^{\mathrm{b}}$ & & \\
$14: 0$ & $0.82 \pm 0.08 \mathrm{a}$ & $0.81 \pm 0.06 \mathrm{a}$ \\
$16: 0$ & $11.09 \pm 0.07 \mathrm{a}$ & $11.02 \pm 0.05 \mathrm{a}$ \\
$16: 1$ & $0.81 \pm 0.04 \mathrm{a}$ & $0.82 \pm 0.06 \mathrm{a}$ \\
$18: 0$ & $4.94 \pm 0.11 \mathrm{a}$ & $4.98 \pm 0.07 \mathrm{a}$ \\
$18: 1$ & $25.01 \pm 0.07 \mathrm{a}$ & $24.97 \pm 0.09 \mathrm{a}$ \\
$18: 2$ & $49.52 \pm 0.09 \mathrm{a}$ & $49.58 \pm 0.06 \mathrm{a}$ \\
$18: 3$ & $7.01 \pm 0.07 \mathrm{a}$ & $6.96 \pm 0.11 \mathrm{a}$ \\
$20: 0$ & $0.41 \pm 0.05 \mathrm{a}$ & $0.46 \pm 0.05 \mathrm{a}$ \\
Peroxide value, PV (meq/kg oil) & $0.98 \pm 0.02 \mathrm{~b}$ & $0.06 \pm 0.02 \mathrm{a}$ \\
Total phenols $(\mathrm{mg}$ gallic acid/kg oil) & $130.35 \pm 8.02 \mathrm{~b}$ & $1.02 \pm 0.76 \mathrm{a}$ \\
Tocopherols $(\mathrm{mg} \alpha$-tocopherol $/ \mathrm{kg}$ oil $)$ & $388.61 \pm 6.84 \mathrm{~b}$ & $0.72 \pm 0.09 \mathrm{a}$ \\
\hline
\end{tabular}

${ }^{\text {a }}$ Values represent means \pm SD $(\mathrm{n}=3)$ Table 2Antiradical activity in DPPH, $\beta$-carotene-linoleic acid emulsion, and Rancimat assays and partition coefficient of the antioxidants 


\begin{tabular}{|c|c|c|c|c|c|c|}
\hline Parameter & Gallic acid & Methyl gallate & Propyl gallate & Octyl gallate & Dodecyl gallate & Stearyl gallate \\
\hline \multicolumn{7}{|l|}{$\overline{\mathrm{RSA}} \%$} \\
\hline $10 \mu \mathrm{M}$ & $28.08 \pm 0.59 \mathrm{~b}$ & $21.16 \pm 0.68 \mathrm{a}$ & $20.68 \pm 1.06 \mathrm{a}$ & $20.06 \pm 0.76 \mathrm{a}$ & $20.18 \pm 1.17 \mathrm{a}$ & $19.87 \pm 1.09 \mathrm{a}$ \\
\hline $20 \mu \mathrm{M}$ & $36.45 \pm 0.79 \mathrm{c}$ & $29.05 \pm 0.79 \mathrm{ab}$ & $0.62 \mathrm{~b}$ & $27.78 \pm 0.80 \mathrm{ab}$ & $28.69 \pm$ & $27.01 \pm 0.72 \mathrm{a}$ \\
\hline $30 \mu \mathrm{M}$ & $49.74 \pm 0.49 \mathrm{~b}$ & $40.32 \pm 0.46 \mathrm{a}$ & $40.27 \pm 0.90 \mathrm{a}$ & $39.52 \pm 1.24 \mathrm{a}$ & $39.16 \pm 0.46 \mathrm{a}$ & $38.66 \pm 0.65 \mathrm{a}$ \\
\hline $40 \mu \mathrm{M}$ & $63.16 \pm 1.06 \mathrm{c}$ & $50.24 \pm 0.92 \mathrm{ab}$ & $51.40 \pm 0.55 \mathrm{~b}$ & $50.11 \pm 0.60 \mathrm{ab}$ & $49.87 \pm 0.59 \mathrm{ab}$ & $49.17 \pm 0.73 \mathrm{a}$ \\
\hline $50 \mu \mathrm{M}$ & $75.09 \pm 0.63 \mathrm{c}$ & $64.17 \pm 1.23 \mathrm{ab}$ & $65.56 \pm 0.74 \mathrm{~b}$ & $63.77 \pm 0.58 \mathrm{ab}$ & $63.05 \pm 0.79 \mathrm{a}$ & $62.39 \pm 1.13 \mathrm{a}$ \\
\hline $\begin{array}{l}\mathrm{IC}_{50}(\mu \mathrm{M}) \\
\mathrm{BCB} \%\end{array}$ & $29.58 \pm 0.36 \mathrm{a}$ & $38.40 \pm 0.44 \mathrm{bc}$ & $37.66 \pm 0.59 \mathrm{~b}$ & $38.88 \pm 0.41 \mathrm{bc}$ & $39.17 \pm 0.89 \mathrm{bc}$ & $39.87 \pm 0.72 \mathrm{c}$ \\
\hline $10 \mu \mathrm{M}$ & $17.36 \pm 0.29 \mathrm{a}$ & $20.22 \pm 0.45 \mathrm{~b}$ & $20.56 \pm 0.93 \mathrm{~b}$ & $22.64 \pm 0.27 \mathrm{c}$ & $25.06 \pm 0.49 \mathrm{~d}$ & $18.07 \pm 0.17 \mathrm{a}$ \\
\hline $20 \mu \mathrm{M}$ & $25.02 \pm 0.27 \mathrm{a}$ & $28.07 \pm 0.49 \mathrm{~b}$ & $27.94 \pm 0.66 \mathrm{~b}$ & $30.21 \pm 0.15 \mathrm{c}$ & $34.72 \pm 0.75 \mathrm{~d}$ & $26.88 \pm 0.45 \mathrm{~b}$ \\
\hline $30 \mu \mathrm{M}$ & $32.88 \pm 0.22 \mathrm{a}$ & $35.09 \pm 0.31 \mathrm{~b}$ & $36.16 \pm 0.76 \mathrm{c}$ & $36.87 \pm 0.13 \mathrm{c}$ & $42.12 \pm 0.15 \mathrm{~d}$ & $32.61 \pm 0.11 \mathrm{a}$ \\
\hline $40 \mu \mathrm{M}$ & $43.75 \pm 0.29 \mathrm{~b}$ & $44.28 \pm 0.73 \mathrm{~b}$ & $46.37 \pm 0.72 \mathrm{c}$ & $48.06 \pm 0.34 \mathrm{~d}$ & $52.11 \pm 0.11 \mathrm{e}$ & $40.39 \pm 0.22 \mathrm{a}$ \\
\hline $50 \mu \mathrm{M}$ & $58.46 \pm 0.45 \mathrm{ab}$ & $60.34 \pm 0.25 \mathrm{c}$ & $59.55 \pm 0.65 \mathrm{bc}$ & $63.60 \pm 0.31 \mathrm{~d}$ & $69.08 \pm 0.11 \mathrm{e}$ & $58.07 \pm 0.87 \mathrm{a}$ \\
\hline $\mathrm{IC}_{50}(\mu \mathrm{M})$ & $44.37 \pm 0.45 \mathrm{~d}$ & $42.85 \pm 0.12 \mathrm{c}$ & $42.32 \pm 0.13 \mathrm{c}$ & $39.75 \pm 0.21 \mathrm{~b}$ & $35.10 \pm 0.32 \mathrm{a}$ & $45.82 \pm 0.35 \mathrm{e}$ \\
\hline OSI (h) & $4.72 \pm 0.15 \mathrm{a}$ & $5.32 \pm 0.45 \mathrm{~b}$ & $6.20 \pm 0.16 \mathrm{~d}$ & $5.81 \pm 0.14 \mathrm{c}$ & $5.73 \pm 0.05 \mathrm{c}$ & $5.34 \pm 0.03 \mathrm{~b}$ \\
\hline $\log \mathrm{P}$ & $-0.47 \pm 0.06 \mathrm{a}$ & $0.66 \pm 0.05 \mathrm{~b}$ & $0.82 \pm 0.03 \mathrm{c}$ & $0.97 \pm 0.07 \mathrm{~d}$ & $1.24 \pm 0.04 \mathrm{e}$ & $1.65 \pm 0.07 \mathrm{f}$ \\
\hline
\end{tabular}

Values $\pm \mathrm{SD}(\mathrm{n}=3)$ within a row with the same lowercase letters are not significantly different at $p<$ 0.05.RSA: Radical scavenging activity in $\mathrm{DPPH} ; I_{50}$ : The concentration of antioxidant required to scavenge $50 \%$ of free radicals; $B C B$ : $\beta$-carotene-linoleic acid assay; OSI: Oxidative stability index obtained by Rancimat assay; $\log P$ : partition coefficient.Table 3 Kinetic parameters characterizing inhibited peroxidation of purified soybean oil containing antioxidants studied at $60{ }^{\circ} \mathrm{C}{ }^{\text {a }}$

\begin{tabular}{llll}
\hline Treatment & Primary oxidation kinetic parameters & Primary oxidation kinetic parameters & Primary oxidation kineti \\
\hline & $\mathrm{IP} \mathrm{b}$ & $K_{i}{ }^{\mathrm{c}}$ & $W_{\mathrm{AH}} \mathrm{d}$ \\
Control & $5.99 \pm 0.15 \mathrm{a}$ & $3048 \pm 5.5 \mathrm{e}$ & - \\
Gallic acid & $388.34 \pm 1.06 \mathrm{~d}$ & $34.62 \pm 1.64 \mathrm{c}$ & $8.58 \pm 0.00 \mathrm{~d}$ \\
Methyl gallate & $457.31 \pm 2.45 \mathrm{~g}$ & $27.64 \pm 0.17 \mathrm{a}$ & $7.33 \pm 0.06 \mathrm{a}$ \\
Propyl gallate & $448.82 \pm 1.07 \mathrm{f}$ & $30.89 \pm 0.42 \mathrm{~b}$ & $8.39 \pm 0.01 \mathrm{~b}$ \\
Octyl gallate & $396.73 \pm 2.84 \mathrm{e}$ & $35.76 \pm 0.61 \mathrm{c}$ & $9.10 \pm 0.00 \mathrm{e}$ \\
Dodecyl gallate & $366.31 \pm 2.65 \mathrm{c}$ & $38.95 \pm 0.24 \mathrm{~d}$ & $9.90 \pm 0.01 \mathrm{f}$ \\
Stearyl gallate & $336.77 \pm 2.63 \mathrm{~b}$ & $35.79 \pm 1.01 \mathrm{c}$ &
\end{tabular}

${ }^{\mathrm{a}}$ Means $\pm \mathrm{SD}$ within a column with the same lowercase letters are not significantly different at $p<0.05{ }^{\mathrm{b}}$ Induction period (h). ${ }^{\mathrm{c}}$ Oxidation rate during the initiation phase of peroxidation (meq/ $\left.\mathrm{kg} \mathrm{h}\right) .{ }^{\mathrm{d}}$ Mean rate of antioxidant consumption (M/s). ${ }^{\mathrm{e}}$ Stabilization factor. ${ }^{\mathrm{f}}$ Oxidation rate ratio. ${ }^{\mathrm{g}}$ Antioxidant activity. ${ }^{\mathrm{h}}$ Critical reverse micelle concentration of lipid hydroperoxides (meq/ $\mathrm{kg}) .{ }^{\mathrm{i}} p$-Anisidine value at IP ${ }^{\mathrm{j}} p$-Anisidine value in the middle point of the propagation phase. ${ }^{\mathrm{k}} p$-Anisidine value in the end point of the propagation phase.

\section{Table 4}

The changes in water content, interfacial tension, and micelle size of the bulk soybean oil containing antioxidants studied at $60{ }^{\circ} \mathrm{C}^{\mathrm{a}}$

\begin{tabular}{|c|c|c|c|c|}
\hline Sample & Water content $(\% \mathrm{w} / \mathrm{w})^{\mathrm{b}}$ & Water content $(\% \mathrm{w} / \mathrm{w})^{\mathrm{b}}$ & Water content $(\% \mathrm{w} / \mathrm{w})^{\mathrm{b}}$ & Water content $(\% \mathrm{w} / \mathrm{w}$ \\
\hline & $\mathrm{t}=0^{\mathrm{c}}$ & $\mathrm{IP}^{\mathrm{d}}$ & $\mathrm{P}_{\mathrm{m}}{ }^{\mathrm{e}}$ & $\mathrm{P}_{\mathrm{e}}{ }^{\mathrm{f}}$ \\
\hline Control & $0.022 \mathrm{Aa}$ & $0.036 \mathrm{Ba}$ & $0.057 \mathrm{Cb}$ & $0.078 \mathrm{Dc}$ \\
\hline Gallic acid & $0.023 \mathrm{Aa}$ & $0.046 \mathrm{Bb}$ & $0.071 \mathrm{Ce}$ & $0.099 \mathrm{De}$ \\
\hline
\end{tabular}




\begin{tabular}{lllll}
\hline Sample & Water content $(\% \mathrm{w} / \mathrm{w})^{\mathrm{b}}$ & Water content $(\% \mathrm{w} / \mathrm{w}){ }^{\mathrm{b}}$ & Water content $(\% \mathrm{w} / \mathrm{w})^{\mathrm{b}}$ & Water content $(\% \mathrm{w} / \mathrm{w}$ \\
\hline Methyl gallate & $0.023 \mathrm{Aa}$ & $0.058 \mathrm{Bd}$ & $0.064 \mathrm{Ccd}$ & $0.069 \mathrm{Db}$ \\
Propyl gallate & $0.024 \mathrm{Aa}$ & $0.054 \mathrm{Bc}$ & $0.066 \mathrm{Cd}$ & $0.086 \mathrm{Dd}$ \\
Octyl gallate & $0.022 \mathrm{Aa}$ & $0.068 \mathrm{Be}$ & $0.081 \mathrm{Cf}$ & $0.087 \mathrm{Dd}$ \\
Dodecyl gallate & $0.023 \mathrm{Aa}$ & $0.036 \mathrm{Ba}$ & $0.053 \mathrm{Ca}$ & $0.062 \mathrm{Da}$ \\
Stearyl gallate & $0.025 \mathrm{Aa}$ & $0.057 \mathrm{Bd}$ & $0.062 \mathrm{Cc}$ & $0.086 \mathrm{Dd}$ \\
\hline
\end{tabular}

${ }^{a}$ Means within a column with the same lowercase letters are not significantly different at $p<0.05$. Means within a row with the same uppercase letters are not significantly different at $p<0.05$.

b The standard deviations were $<0.003,0.05$, and 26 for water content, interfacial tension, and micelle size, respectively.

${ }^{\mathrm{c}}$ Immediately after preparation.

d Induction period.

e The middle point of the propagation phase.

${ }^{f}$ The end point of the propagation phase.

g Polydispersity indices (PDI) were less than one.

\section{Hosted file}

Figure AOCS.docx available at https://authorea.com/users/450027/articles/548458-effectof-alkyl-chain-length-on-interfacial-performance-of-alkyl-gallates-in-supramolecularoxidation-of-soybean-bulk-phase-oil 